\title{
Colocalization of myostatin and decorin in bovine skeletal muscle
}

\author{
Elke Albrecht' ${ }^{1}$ Xiujuan Liu' ${ }^{2}$, Xiaojing Yang ${ }^{2}$, Ruqian Zhao² , Ludwig Jonas ${ }^{3}$, Steffen Maak' \\ 'Leibniz Institute for Farm Animal Biology (FBN), Research Unit Muscle Biology and Growth, Dummerstorf, Germany, \\ ${ }^{2}$ Nanjing Agricultural University, Key Laboratory of Animal Physiology \& Biochemistry, Nanjing, P.R. China, ${ }^{3}$ University \\ of Rostock, Center for Electron Microscopy, Institute for Pathology, Rostock, Germany
}

\begin{abstract}
The objectives of this study were to investigate the expression and localization of myostatin (MSTN) and decorin (DCN) in bovine skeletal muscle and to find associations with muscle fibre and adipocyte development. Samples of two muscles, known for differences in meat quality and fibre composition, namely longissimus muscle (LD) and semitendinosus muscle (ST), were obtained from 18 months old bulls of the $F_{2}$ generation of a Charolais $\times$ Holstein cross. Individual muscle sections were stained for determination of size and type of muscle fibres and immunohistochemical detection of the proteins. The mRNA abundance and protein expression of MSTN and DCN were quantified by real-time PCR and Western blot, respectively. As expected, the ST had more fast fibres, less fibres of the intermediate and the slow type, and less intramuscular fat than the LD. Despite these differences, the mRNA and protein abundance of MSTN was comparable in both muscles. The protein abundance of MSTN inhibitors, namely MSTN propeptide and DCN, was greater in LD, which may have affected the biological activity of mature MSTN. Myostatin propeptide was detected in all muscle fibres; however the mature MSTN was detected to a much lower extent and mainly in slow fibres. Furthermore, MSTN was localized in close proximity to DCN in intermyocellular space, suggesting possible interactions between both proteins and effects on muscle structure and meat quality. The role of MSTN and DCN as well as their interactions in the determination of muscle composition needs to be further elucidated.
\end{abstract}

Keywords: cattle, decorin (DCN), muscle, myostatin (MSTN)

\section{Zusammenfassung}

\section{Co-Lokalisation von Myostatin und Decorin im bovinen Skelettmuskel}

Ziel der Untersuchungen war es, die Expression und Lokalisierung von Myostatin (MSTN) und Decorin (DCN) im bovinen Muskel zu bestimmen und Beziehungen zur Muskelfaser- und Adipozytenentwicklung zu finden. Dazu wurden von 18 Monate alten Bullen der $\mathrm{F}_{2}$ Generation eines Charolais $\times$ Holstein Kreuzungsexperiments Proben von zwei Muskeln (M. Iongissimus dorsi - LD und M. semitendinosus - ST) gewonnen, die für Unterschiede in der Fleischqualität und Faserzusammensetzung bekannt sind. Entsprechend gefärbte Serienschnitte wurden verwendet, um die Größe und das Typenprofil der Muskelfasern zu bestimmen sowie für den immunhistochemischen Nachweis der Proteine. Die mRNA- und Proteinmenge von 
MSTN und DCN wurden außerdem mit real-time PCR und Western Blot quantifiziert. Wie erwartet hatte der ST mehr schnell kontrahierende Fasern und weniger intermediäre und langsam kontrahierende Fasern sowie weniger intramuskuläres Fett als der LD. Trotz dieser Unterschiede wurden in beiden Muskeln vergleichbare MSTN mRNA- und Proteinmengen gemessen. Im LD wurde jedoch mehr MSTN Propeptid und DCN Protein gefunden, die als MSTN Inhibitoren die biologische Aktivität beeinflussen können. Das MSTN Propeptid wurde in allen Muskelfasern nachgewiesen, dagegen die reife Form des MSTN in viel geringerer Menge und hauptsächlich in den langsam kontrahierenden Fasern. Weiterhin wurde MSTN zwischen den Muskelfasern in der Nähe von DCN lokalisiert, was auf mögliche Interaktionen zwischen beiden Proteinen und Effekte auf die Muskelstruktur und Fleischqualität hinweisen könnte. Die Rolle von MSTN und DCN sowie deren Interaktionen bei der Ausprägung der Muskelzusammensetzung bedarf weiterer Untersuchungen.

Schlüsselwörter: Rind, Decorin (DCN), Muskel, Myostatin (MSTN)

\section{Introduction}

Myostatin (MSTN), a member of transforming growth factor type beta (TGF- $\beta$ ) superfamily of growth factors, is a negative regulator of skeletal muscle mass, leading to a significant decrease in muscle mass, muscle fibre cross-sectional area, and muscle protein content when overexpressed (Durieux et al. 2007). Myostatin is secreted into the extracellular matrix where it can interact with Decorin (DCN, Miura et al. 2006). Decorin is a small leucine-rich proteoglycan that modulates the activity of TGF- $\beta$ and other growth factors and thereby influences the processes of proliferation and differentiation in a wide array of physiological and pathological reactions (Brandan et al. 2006). Decorin interferes with muscle cell differentiation and migration and regulates connective tissue formation in skeletal muscle and mRNA expression is therefore higher in foetal skeletal muscle than in neonates and adults (Casar et al. 2004, Yoshida et al. 1998). Sun et al. (2010) reported associations between DCN gene polymorphisms and the birth weight of cattle. Recent studies showed: (1) DCN can bind to MSTN and inhibit MSTN activity (Miura et al. 2006); (2) DCN enhanced the proliferation and differentiation of myogenic cells by suppressing MSTN activity (Kishioka et al. 2008); (3) MSTN administered to proliferating satellite cells depress the synthesis of DCN (McFarland et al. 2007); (4) MSTN inhibits adipogenesis in 3T3-L1 cells, but could not alter lipolysis in fully differentiated adipocytes (Stolz et al. 2008). However, the association between MSTN and DCN in adult muscle of cattle is still uncertain. The objectives of this study were to investigate the expression, localization, and interaction of MSTN and DCN in skeletal muscle of adult cattle and to find associations with muscle fibre and adipocyte development.

\section{Material and methods}

\section{Animals and sampling}

A sample group of 11 bulls, selected from a $\mathrm{F}_{2}$ resource population generated from the founder breeds Charolais and German Holstein (Kühn et al. 2002), was slaughtered at 18 months of age in the research institute's experimental abattoir according to a standardized protocol. All 
animals were cared for and slaughtered according to German rules and regulations for animal care. The experiment was approved by the institutional authorities and by the responsible office of the State of Mecklenburg-Western Pommerania, Germany.

The calves were weaned from their mothers immediately after birth and received a milk replacer diet until day 121 post partum. This diet was gradually replaced by ad libitum access to hay and concentrates. Subsequently, the individuals were kept in a tie-stall barn on a daily semi-ad libitum feed ration, which was composed of chaffed hay and a concentrate (RM 2007; Vollkraft Mischfutterwerke, Rendsburg, Germany) with a hay-to-concentrate ratio of 1:3 and an energy content of $12.7 \mathrm{MJ} \mathrm{ME} / \mathrm{kg}$ dry matter. The ration provided for a maximal average daily weight gain, while still being compatible with ruminant requirements.

Muscle tissue from M. longissimus dorsi (LD) and $M$. semitendinosus (ST) was collected separately for RNA extraction, protein extraction, and histology, immediately frozen in liquid nitrogen, and then stored at $-70^{\circ} \mathrm{C}$ until use. Carcass and meat quality traits were recorded. Brightness was measured with a Minolta CR 200 (Minolta GmbH, Ahrensburg, Germany) in triplicates on the freshly cut surface $24 \mathrm{~h}$ post mortem using the parameter $\mathrm{L}^{*}$ ( $\mathrm{L}=0$ designates black and $L=100$ designates pure white). The water holding capacity was determined by the method descibed by Grosse et al. (1975). Shear force measurement was done $24 \mathrm{~h}$ and 14 days after slaughter as described by Otto and Stang (1975). The intramuscular fat content was obtained in triplicates via the Soxhlet extraction method using petroleum ether as solvent and determined gravimetrically after evaporating the extracting solvent (AOAC 2000).

\section{Histological analysis}

Samples of LD and ST muscles were cryosectioned using a Leica CM3050 S (Leica, Bensheim, Germany) cryostat microtome. The sections ( $10 \mu \mathrm{m}$ thick) were stained with hematoxylin and eosin, for measurement of muscle fiber and fat cell size. Fibre types were detected using actomyosin $\mathrm{Ca}^{2+}$ adenosine triphosphatase stability after alkaline preincubation ( $\left.\mathrm{pH} 10.4\right)$ and staining with azure II (Chroma-Gesellschaft, Schmid, Köngen, Germany) as described by Wegner et al. (2000). The muscle fibre and fat cell traits in individual skeletal muscles were analyzed using an image analysis system equipped with Jenaval microscope (Carl Zeiss, Jena, Germany), Altra20 CCD camera (OSIS, Münster, Germany) and CELL^D image analysis software (OSIS, Münster, Germany). Adipocyte size was measured using the interactive measurement module. Where available, 200 to 300 adipocytes were randomly selected and measured, after following the contour using the interpolating polygon function. In muscle sections containing less adipocytes, all available cells were measured. Muscle fibre traits were measured with a special muscle fibre measurement module (MAS, Freiburg, Germany) of the same system as described in detail by Albrecht et al. (2011). A minimum of 300 muscle fibres per animal in randomly selected muscle fibre primary bundles, usually 4 to 6 fields of one section, were measured and classified.

\section{RNA isolation and real-time RT-PCR}

Total RNA was isolated from LD and ST muscles using Trizol reagent (Invitrogen, Karlsruhe, Germany) according to manufacturer's instructions. Concentration and quality of the extracted RNA were measured using a NanoDrop ND-1000 spectrophotometer (Peqlab Biotechnologie, 
Erlangen, Germany) and the StdSens RNA Assay of an Experion Automated Electrophoresis System (BioRad Laboratories, Munich, Germany). The RQI numbers of all samples were between 7.7 and 9.4. The iScriptTM cDNA Synthesis Kit (Bio-Rad Laboratories, Munich, Germany) was used to synthesize cDNA from $100 \mathrm{ng}$ of total RNA from each sample according to manufacturer's instructions. A negative control, without reverse transcriptase, was processed for each sample. The abundance of mRNA for ribosomal protein S18 (RPS18), MSTN, and DCN was quantified by real-time RT-PCR (iCycler, BioRad Laboratories, Munich, Germany). PCR was performed in 40 cycles with $180 \mathrm{~s}$ at $94^{\circ} \mathrm{C}, 10 \mathrm{~s}$ at $94^{\circ} \mathrm{C}$ followed by $30 \mathrm{~s}$ at $60^{\circ} \mathrm{C}$ and $45 \mathrm{~s}$ at $70^{\circ} \mathrm{C}$. The sequences of specific bovine primers used were as follows: RPS18 (GenBank accession No: NM_001033614; product size: $218 \mathrm{bp}$ ) forward: 5'-CTT AAA CAG ACA GAA GGA CGT GAA-3', reverse: 5'-CCA CAC ATT ATTTCT TCT TG GACA-3' (Tib Molbiol, Berlin, Germany); DCN (GenBank acc. No: NM_173906; product size: 218 bp) forward: 5'-AAC TCT TTT GCT TGG GCT GA-3', reverse: 5'-CCA GAA GCC TCA TCT TCC AG-3' (Sigma-Aldrich, Munich, Germany); MSTN (GenBank acc. No: NM_001001525; product size: $191 \mathrm{bp}$ ) forward: 5'-GTG TTG CAG AAC TGG CTC AA-3', reverse: 5'-TCA TCA CAA TCA AGC CCA AA-3' (Sigma-Aldrich, Munich, Germany). The specificity of amplification was determined by melting curve analysis and agarose gel electrophoresis. The cDNA structure was checked by sequencing. The reported sequences matched exactly to those published in GenBank. Each cDNA was quantified in triplicate; the average value of each sample minus the corresponding negative control value was used to calculate the cDNA product corresponding to the abundance of mRNA. The mRNA abundance was calculated as pg/ $\mu \mathrm{g}$ total RNA, using the known concentration of standard oligonucleotides and amplification efficiency displayed by the iCycler. The values were normalized to RPS18 mRNA.

\section{Western blotting}

Total protein was extracted from LD and ST muscles using CelLytic MT lyses reagent (SigmaAldrich, Munich, Germany) with protease inhibitor according to manufacturer's instructions. Protein extract, $50 \mu \mathrm{g}$, was mixed with loading buffer and denatured by boiling for $5 \mathrm{~min}$ before loading on a $12.5 \%$ SDS-PAGE $10 \times 10$ mini gel. After electrophoresis, proteins were transferred to a polyvinylidene difluoride (PVDF) membrane. The membrane was blocked with $5 \%$ non-fat dry milk in Tris-buffered saline (TBS) for $1 \mathrm{~h}$ at room temperature. The membranes were than incubated with the respective primary antibodies against MSTN propeptide (mouse anti human, ab37254, Abcam, Cambridge, UK), MSTN (rabbit anti human, AB3239, Millipore, Schwalbach, Germany), or DCN (rabbit anti human, sc-22753, Santa Cruz Biotechnology, Heidelberg, Germany) at $4{ }^{\circ} \mathrm{C}$ overnight. Cross reactivity with the respective bovine proteins were expected due to sequence homologies between synthetic peptides used for antibody generation and bovine sequences. After washing, membranes were incubated with the respective secondary antibodies, either mouse lgG TrueBlot (18-8817) or rabbit lgG TrueBlot (18-8816, eBioscience, Frankfurt, Germany). Antibody label was detected with chemiluminescence substrate (Super Signal West Femto, PIERCE, Rockford, USA) and a Chemocam HR-16 imager (INTAS, Göttingen, Germany). The intensity of specific bands was quantified using Lablmage 1D Electrophoresis Software (Kapelan Bio-Imaging, Leipzig, Germany). Two independent blots were analyzed for each sample, whereby protein of both muscles of one animal was on the same blot. For comparability, individual band volumes were normalized dividing them by the average band volume of the blot. 


\section{Immunohistochemical analysis}

Muscle sections were fixed in ice cold acetone for $10 \mathrm{~min}$. Unspecific bindings of the secondary antibody were blocked using $10 \%$ secondary antibody serum in PBS-Tritonx100 (PBST) for $15 \mathrm{~min}$. Sections were incubated with the respective primary antibody against MSTN propeptide, MSTN (as used for Western blots), or DCN (mouse monoclonal, H00001634-M01, Abnova, Taipei, Taiwan), for $1 \mathrm{~h}$ at room temperature in a humidity chamber. Specific binding of primary antibodies was detected with the respective goat anti mouse or rabbit IgG secondary antibodies labelled with Alexa Fluor 488 (Molecular Probes, Eugene, USA). In MSTN-DCN double labelling experiments, MSTN was detected by an Alexa Fluor 594 labelled goat anti rabbit lgG and the DCN was detected by an Alexa Fluor 488 rabbit anti mouse lgG. Nuclei were counterstained with $1 \mu \mathrm{g} / \mathrm{ml}$ Hoechst 33258 (Sigma-Aldrich, Munich, Germany). Slides were covered using MobiGLOW mounting medium (MoBiTec, Göttingen, Germany) and appropriate cover-slips. Negative controls were incubated omitting the primary antibody. No unspecific binding of the secondary antibodies was detected. Immunofluorescence was visualized with a Nikon Microphot SA fluorescence microscope (Nikon, Düsseldorf, Germany) and an image analysis system equipped with CELL^F software and a CC -12 high resolution colour camera (OSIS, Münster, Germany).

\section{Immune-electron microscopy}

Muscle samples were fixed in $1 \%$ paraformaldehyde, dehydrated and embedded in acryl resin (LRWhite, hardgrade, Plano, Wetzlar, Germany). Samples were cut using an ultramicrotome (Ultracut S, Leica, Wetzlar, Germany) and transferred to grids (Plano, Wetzlar, Germany) and sections were incubated concurrently with antibodies against MSTN and DCN (as used for immunohistochemistry). For detection, secondary antibodies conjugated either to 10-nm (anti rabbit, G7402, Sigma-Aldrich, Munich, Germany) or 5-nm (anti mouse, G7527, Sigma-Aldrich, Munich, Germany) colloidal gold particles were used. The immunogoldlabelled proteins were visualized using a transmission electron microscope Libra 120 (Zeiss, Oberkochen, Germany).

\section{Statistical analysis}

Statistical analysis was performed using the SAS statistical software version 9.2 (SAS Inst. Inc. 2008). For comparison of the two muscles, data were analyzed by ANOVA using the MIXED procedure with fixed factor muscle and random animal. The t-test was used as post-hoc test with $P \leq 0.05$ as threshold for significant differences.

Relationships between traits were calculated as Pearson's-correlation coefficients using the CORR procedure of SAS.

\section{Results and discussion}

The study was conducted to investigate MSTN and DCN expression in muscles showing different muscle fibre size and profile, different meat quality properties, and intramuscular fat deposition. Meat quality and muscle structure data (Table 1) showed the expected clear difference between LD and ST muscles. Values of brightness, water holding capacity, and 
shear force were lower $(P \leq 0.02)$ and intramuscular fat content was higher $(P<0.01)$ in LD. Based on myofibrillar ATPase activity, ST displayed a larger proportion $(P<0.01)$ of fast fibres and a reduced proportion $(P<0.01)$ of slow fibres compared with LD (Table 1). The muscle fibre area was larger $(P \leq 0.02)$ for all three types in $S T$. The LD had therefore a higher $(P<0.01)$ muscle fibre density than ST. Intramuscular fat cell size was not different $(P=0.39)$ between muscles. Nevertheless, the samples varied sufficiently to enable the detection of possible associations between these traits and MSTN and DCN expression.

Table 1

Meat quality and muscle structure traits of two muscles in 18 months old bulls

\begin{tabular}{lcccr}
\hline Trait & $\begin{array}{c}\text { Longissimus } \\
\text { muscle }\end{array}$ & $\begin{array}{c}\text { Semitendinosus } \\
\text { muscle }\end{array}$ & SE & $P$ \\
\hline Meat quality & & & & \\
Brightness, $L^{*}$ & 36.2 & 38.6 & 0.7 & 0.023 \\
Water holding capacity, \% & 31.4 & 37.1 & 2.0 & 0.023 \\
Shear force 24 $\mathrm{h}, \mathrm{kg}$ & 15.9 & 22.2 & 1.0 & $<0.001$ \\
Shear force 14 $\mathrm{d}$, kg & 10.3 & 14.9 & 0.7 & $<0.001$ \\
Intramuscular fat content, \% & 5.0 & 2.4 & 0.6 & 0.003 \\
Muscle fibre cross sectional area, $\mu \mathrm{m}^{2}$ & & & & \\
Total & 2802 & 4889 & 317 & $<0.001$ \\
Fast & 3481 & 5713 & 364 & $<0.001$ \\
Intermediate & 2462 & 3452 & 290 & 0.022 \\
Slow & 1949 & 3719 & 305 & 0.001 \\
Muscle fibre type profile, \% & & & & \\
Fast & 56.7 & 72.1 & 2.2 & $<0.001$ \\
Intermediate & 28.8 & 17.7 & 1.8 & $<0.001$ \\
Slow & 14.5 & 10.1 & 1.3 & 0.014 \\
Muscle fibre number per $\mathrm{cm}^{2}$ & 36299 & 22602 & 1983 & $<0.001$ \\
Fat cell diameter, $\mu \mathrm{mm}$ & 66.2 & 62.6 & 3.4 & 0.459 \\
\hline
\end{tabular}

The mRNA abundance of DCN and MSTN (Figure 1) was not significantly different between the muscles $(P \geq 0.12)$. A fibre type specific MSTN expression was mentioned in a review by Kobolák \& Gócza (2002). Carlson et al. (1999) found higher MSTN expression in fast muscles than in slow type muscles and a correlation between the level of MSTN mRNA and the percentage of MyHC Illb in muscle. The difference in fibre type composition between LD and ST in our study was not accompanied by different MSTN mRNA levels. Posttranscriptional modifications and protein interactions may play a greater role. The used antibodies were able to discriminate between the mature form of MSTN and its propeptide. By means of Western blotting, the propeptide was detected at $\sim 23 \mathrm{kDa}$, whereas the mature MSTN migrated to $\sim 26 \mathrm{kDa}$. This was also described by McPherron et al. (1997) and Sharma et al. (1999), suggesting a homodimerization. The relative quantification revealed higher amounts of MSTN propeptide and DCN in LD ( $P=0.07$ and $P<0.01$, respectively) compared to ST (Figure 2). The DCN antibody detected two bands, one at $\sim 40 \mathrm{kDa}$, which corresponds to the theoretical size of the DCN core protein (http://www.uniprot.org/uniprot/P21793), and a second band around $60 \mathrm{kDa}$, which is caused by an undefined number of glycosaminoglycan chains (Wight et al. 1991). A protein band of similar size was also described by Eggen et al. (1994) for bovine muscle. 


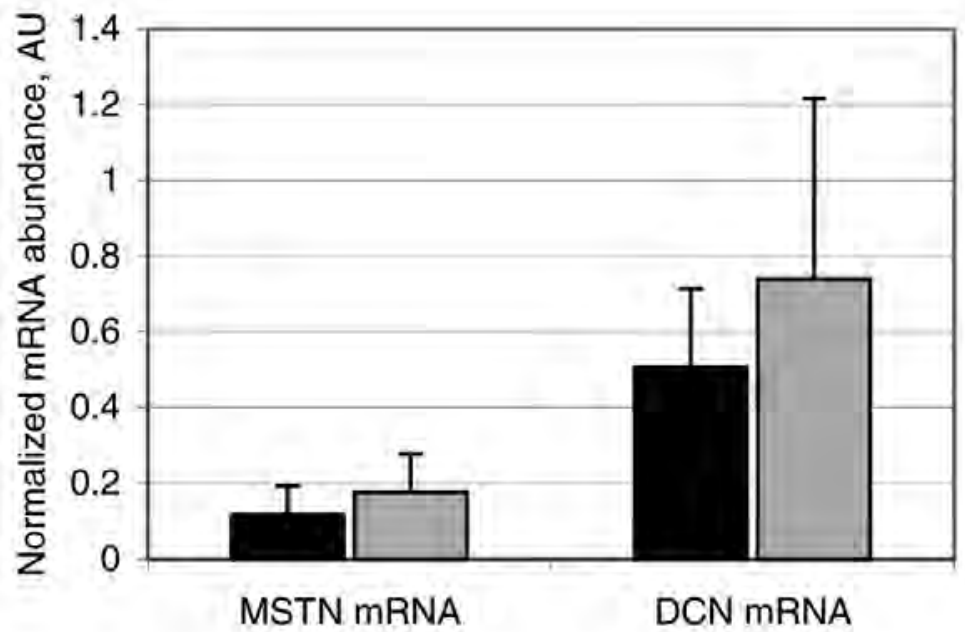

a. longissimus $\square M$. semitendinosus

Figure 1

Abundance of myostatin (MSTN) and decorin (DCN) mRNA in two muscles of 18 months old bulls, normalized to RPS18 mRNA (AU - arbitrary units)

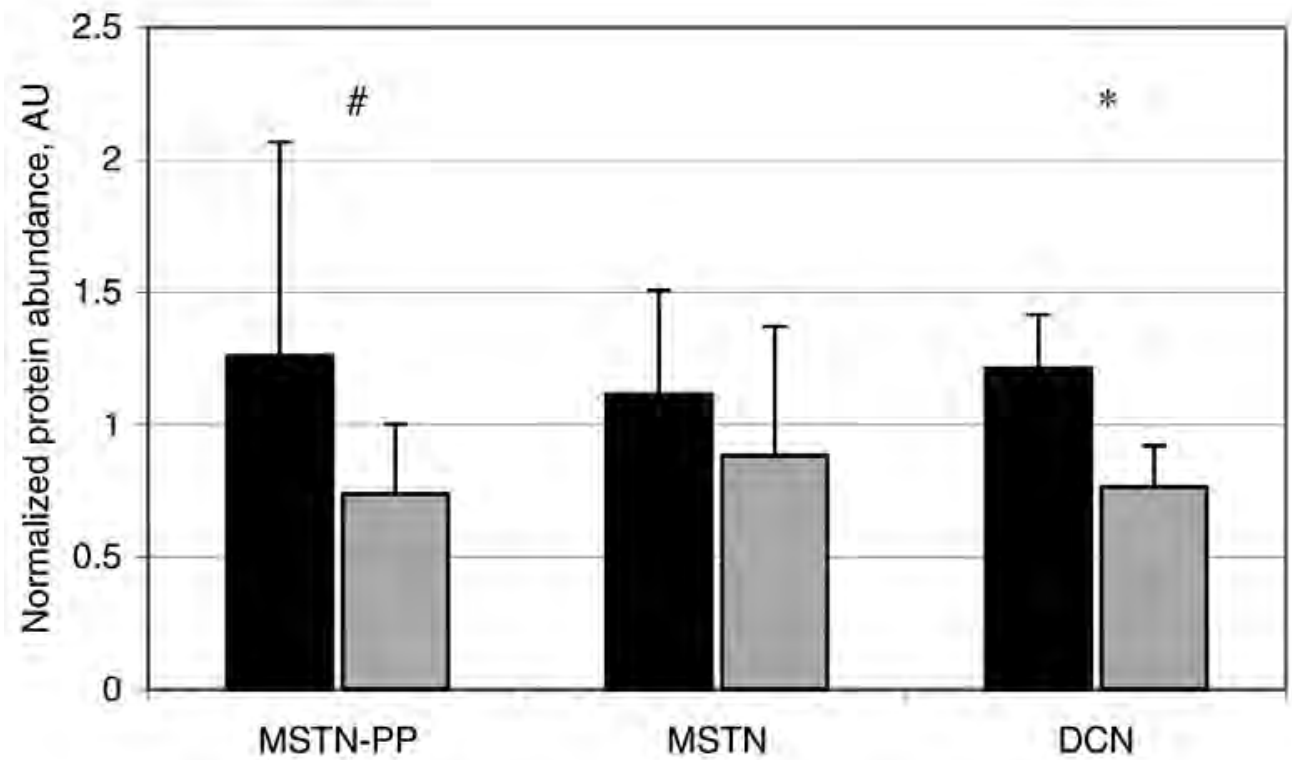

M. longissimus $\square$ M. semitendinosus

\section{Figure 2}

Normalized protein abundance (arbitrary units - AU) of Myostatin (MSTN) propeptide, mature MSTN, and decorin (DCN) in M. longissimus and M. semitendinosus (\# $\left.P<0.1,{ }^{*} P<0.05\right)$ 
Decorin can affect morphogenesis of the intramuscular connective tissue that supports muscle fibres, which is important for the tenderness of meat (McCormick 1999). An increased DCN level could affect the formation of collagen fibres and therefore negatively influence meat quality. However at 18 months of age, the LD had lower shear force values despite the higher DCN protein abundance. Thus, a direct association between protein abundance and meat quality traits could not be detected.

It is well known that overexpression of MSTN elicits a significant decrease in muscle mass, muscle fibre cross-sectional area, and muscle protein content (Durieux et al. 2007). On the other hand, the MSTN-null genotype produces "double muscling « in mice (McPherron et al. 1997) and cattle (McPherron \& Lee 1997). The absolute amount of MSTN expressed in skeletal muscle is only one indicator for its biological activity. There are several inhibitors of MSTN activity among them the MSTN propeptide (Dickson 2009), and DCN (Miura et al. 2006). Interactions between these proteins require a physical proximity. We therefore investigated the localization of mature MSTN, its propeptide, and DCN. Myostatin propeptide was detected in all muscle fibres, with varying intensities, but was never seen outside the muscle fibres (data not shown). The mature form of MSTN was detected in slow myofibres and in the intermyocellular space. For DCN and the mature form of MSTN, immunohistochemical and electron microscopic studies showed a distinct distribution of the proteins and a partial colocalization (Figure 3,4). Both proteins were often detected in close proximity to slow muscle fibres in the intermyocellular space (Figure 3) or in connective tissue in the neighbourhood of developing adipocytes. The colocalization of MSTN and DCN was supported by electron microscopic findings (Figure 4).

This is the first report of a colocalization in bovine skeletal muscle and may be indicative for an interaction. However, colocalization is only a first indicator for protein-protein interactions. Miura et al. (2006) demonstrated that DCN binds to MSTN in rat skeletal muscle and thus, modulates its biological activity. If DCN binds to MSTN and sequesters it in a biologically inactive state (Kishioka et al. 2008) surrounding muscle fibres could exhibit a larger growth. Although the mRNA abundance did not differ for MSTN and DCN between the two investigated muscles and the MSTN protein amount was similar, we detected significant differences in the protein amounts of the MSTN inhibitors MSTN propeptide and DCN. This could be an indicator for a muscle specific regulation of the MSTN action and consequently contribute to the different fibre properties in LD and ST. Further investigations are necessary to elucidate the role of MSTN and DCN in muscle development and composition of cattle. The first demonstration of colocalization of MSTN and DCN in bovine skeletal muscle provides evidence for a similar mechanism of MSTN regulation as previously described for the rat.

\section{Acknowledgements}

This study was supported by the Federal Ministry of Food, Agriculture, and Consumer Protection of Germany and The Agricultural Ministry of China (grant no. 26/04-05). The authors thank Karola Marquardt, Elke Schwitulla, Simone Rackow, and Gerhard Fulda for excellent technical assistance. 

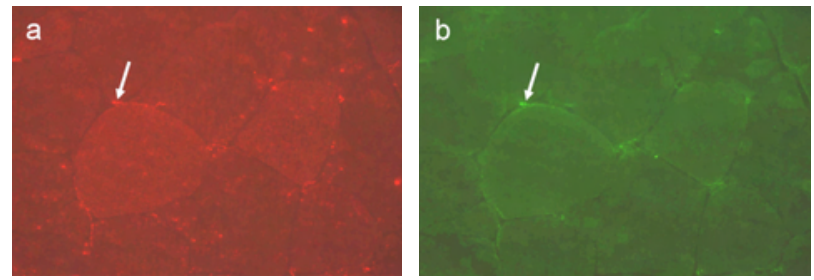

Figure 3

Immunohistochemical detection of MSTN (a: rabbit anti MSTN and Alexa Fluor 594 goat anti rabbit $\operatorname{lgG}$ ) and DCN (b: mouse anti DCN and Alexa Fluor 488 rabbit anti mouse $\operatorname{lgG}$ ) in muscle cross sections and the respective, magnified overlay (c) of
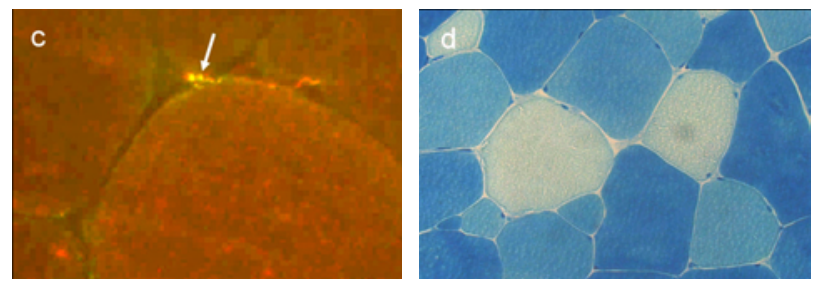
double labeled section, and fibre typing in a serial section (d). Arrows show colocalization of MSTN and DCN, indicated by yellow color.
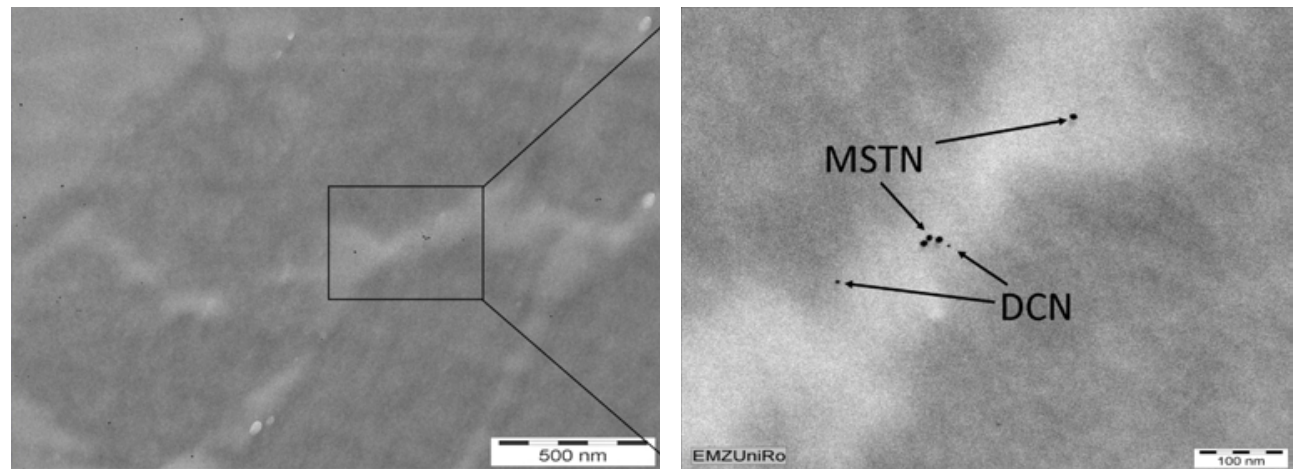

Figure 4

Immune electron microscopic detection of MSTN (rabbit anti MSTN, $10 \mathrm{~nm}$ colloidal gold labelled anti rabbit lgG) and DCN (mouse anti DCN, $5 \mathrm{~nm}$ colloidal gold labelled anti mouse lgG)

\section{References}

Albrecht E, Gotoh T, Ebara F, Xu JX, Viergutz T, Nürnberg G, Maak S, Wegner J (2011) Cellular conditions for intramuscular fat deposition in Japanese Black and Holstein steers. Meat Sci 89, 13-20

AOAC (2000) Association of Official Agricultural Chemists. Official methods of analysis. 17th ed., Washington, DC, USA

Brandan E, Retamal C, Cabello-Verrugio C, Marzolo MP (2006) The low density lipoprotein receptor-related protein functions as an endocytic receptor for decorin. J Biol Chem 281, 31562-31571

Carlson CJ, Booth FW, Gordon SE (1999) Skeletal muscle myostatin mRNA expression is fibre-type specific and increases during hindlimb unloading. Am J Physiol 277, R601-606

Casar JC, McKechnie BA, Fallon JR, Young MF, Brandan E (2004) Transient up-regulation of biglycan during skeletal muscle regeneration: delayed fibre growth along with decorin increase in biglycan-deficient mice. Dev Biol 268, 358-371

Dickson G (2009) Adeno-associated virus-8-mediated intravenous transfer of myostatin propeptide leads to systemic functional improvements of slow but not fast muscle. Rejuvenation Res 12, 85-94

Durieux AC, Amirouche A, Banzet S, Koulmann N, Bonnefoy R, Pasdeloup M, Mouret C, Bigard X, Peinnequin A, Freyssenet $D$ (2007) Ectopic expression of myostatin induces atrophy of adult skeletal muscle by decreasing muscle gene expression. Endocrinology 148, 3140-3147 
Eggen KH, Malmstrøm A, Loset SO (1994) Decorin and a large dermatan sulfate proteoglycan in bovine striated muscle. Biochem Biophys Acta 1204, 287-297

Grosse F, Bretschneider U, Saß G (1975) A method for direct determination of juice expressed from raw meat 29, 104 [in Germann]

Kishioka Y, Thomas M, Wakamatsu J, Hattori A, Sharma M, Kambadur R, Nishimura T (2008) Decorin enhances the proliferation and differentiation of myogenic cells through suppressing myostatin activity. J Cell Physiol 215, 856-867

Kobolák J, Gócza E (2002) The role of the myostatin protein in meat quality - a review. Arch Tierz 45, 159-170

Kühn C, Bellmann O, Voigt J, Wegner J, Guiard V, Ender K (2002) An experimental approach for studying the genetic and physiological background of nutrient transformation in cattle with respect to nutrient secretion and accretion type. Arch Tierz 45, 317-330

McCormick RJ (1999) Extracellular modifications to muscle collagen: implications for meat quality. Poultry Sci $78,785-791$

McFarland DC, Velleman SG, Pesall JE, Liu C (2007) The role of myostatin in chicken (Gallus domesticus) myogenic satellite cell proliferation and differentiation. Gen Comp Endocrinol 151, 351-357

McPherron AC, Lawler AM, Lee SJ (1997) Regulation of skeletal muscle mass in mice by a new TGF-beta superfamily member. Nature $387,83-90$

McPherron AC, Lee SJ (1997) Double muscling in cattle due to mutations in the myostatin gene. Proc Natl Acad Sci 94, 12457-12461

Miura T, Kishioka Y, Wakamatsu J, Hattori A, Hennebry A, Berry CJ, Sharma M, Kambadur R, Nishimura T (2006) Decorin binds myostatin and modulates its activity to muscle cells. Biochem Biophys Res Commun 340, 675-680

Otto E, Stang N (1975) Basic investigations into beeftenderness estimation. 1stCommunication: Methodological studies on meat tenderness. Arch Tierz 18, 301-310 [in Germann]

Sharma M, Kambadur R, Matthews KG, Somers WG, Devlin GP, Conaglen JV, Fowke PJ, Bass JJ (1999) Myostatin, a transforming growth factor-beta superfamily member, is expressed in heart muscle and is upregulated in cardiomyocytes after infarct. J Cell Physiol 180, 1-9

Stolz LE, Li D, Qadri A, Jalenak M, Klaman LD, Tobin JF (2008) Administration of myostatin does not alter fat mass in adult mice. Diabetes Obes Metab 10, 135-142

Sun J, Gu C, Zhang C, Lei C, Fang X, Jin Q, Chen D, Shi X, Du Y, Chen H (2010) Association of polymorphisms of the DCN gene with growth traits in cattle. Arch Tierz 53, 119-121

Wegner J, Albrecht E, Fiedler I, Teuscher F, Papstein HJ, Ender K (2000). Growth- and breed-related changes of muscle fiber characteristics in cattle. J Anim Sci 78, 1485-1496

Wight TN, Heinegard DK, Hascall VC (1991) Proteoglycans: Structure and function. In: Hay ED (ed) Cell Biology of Extracellular Matrix, 2nd ed. Plenum Press, New York, USA, 45-78

Yoshida N, Yoshida S, Koishi K, Masuda K, Nabeshima Y (1998) Cell heterogeneity upon myogenic differentiation: down-regulation of MyoD and Myf-5 generates 'reserve cells'. J Cell Sci 111, 769-779

Received 2 December 2010, accepted 4 March 2011.

Corresponding author:

Elke Albrecht

email: elke.albrecht@fbn-dummerstorf.de

Leibniz Institute for Farm Animal Biology, Muscle Biology and Growth, Wilhelm-Stahl-Allee 2, 18196 Dummerstorf, Germany 